\title{
استخدام وسائل كلمات المقاطعة لترقية قدرة كتابة مفردات اللغة العربية
}

\section{| (إعداد}

\section{${ }^{1}$ Yuni Yusra Harahap, ${ }^{2}$ Ismail Bharuddin}

yuniyusra@gmail.com

Pendidikan Bahasa Arab IAIN Padangsidimpuan

$$
\begin{aligned}
& \text { استخدام وسائل كلمات المتقاطعة ترقية لقدرة كتابة مفردات اللغة العربية، المشكلات الأساسية في } \\
& \text { هذا البحث هي قدرة الكتابة بعض التلاميذ منخفضة، لأن قلة يستخدم الوسائل في عملية التعليم. والنوع } \\
& \text { هذا البحث هو بحث العمل في الفصل. شخص البحث يتكون خمسة وثلاثون شخصا. وأما نتائج البحث } \\
& \text { أن ترقية قدرة الكتابة للتلاميذ بوسائل كلمات المتقاطعة، تزود النتيجة من الامتحان تقوم الباحثة والنتيجة }
\end{aligned}
$$

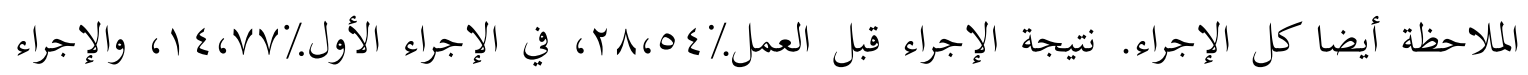

$$
\begin{aligned}
& \text { الثأني.10\%، الن. نظر من النتيجة الإجراء قبل العمل، الإجراء الأول إلى الإجراء الثأني تدل الترقية جملة } \\
& \text { الدرجة التى تزود في كل الامتحان. } \\
& \text { الكلمة المفتوحة: وسائل كلمات المتقاطعة ؛ ترقية قدرة كتابة مفردات اللغة العربية }
\end{aligned}
$$

\begin{abstract}
Abstrak
Penggunaan media penggalan kata mampu meningkatkan kemampuan menulis siswa yang masih rendah yang disebabkan oleh kurangnya penggunaan media pembelajaran, jenis penelitian ini adalah metode penelitian tindakan kelas. Hasil penelitian ini menunjukkan meningkatnya kemampuan menulis siswa sebelum dan sesudah dilakukan tindakan. Kesimpulan penelitian ini adalah terdapatnya peningkatan kemampuan menulis siswa menggunakan media penggalan kata
\end{abstract}

Keyword: Media penggalan kata-kata; Peningkatan kemampuan menulis kosa kata bahasa arab 
الوسائل هي أي شيء يمكن استشعاره ويعمل كوسيل أو وسيلة أو أداة لعملية الاتصال (عملية التعليم والتعليم)' . وفق Gerlach و Ely، بأن وسائل التعليم تأتي من الوسائل اللاتيني وهو حرفيًا متوسط أو وسيط أو مقدمة. في اللغة العربية، تكون الوسائل أو مقدمة لرسالة من المرسل إلى مستلم الرسالة.وسائل الإعلام إذا فهمت أن جميع الخطوط العريضة هي إنسانية أو مادية أو أحداث تبني ظروفًا تجعل التلاميذ قادرين على الحصول على المعرفة أو المهارات أو المواقف. وبهذا المعنى، فإن المعلم والكتاب المدرسي والبيئة المدرسية هي وسائل الإعلامَ' وتعني وسائل الإعلام حرفيًا الوسالة أو المقدمةووتعرف جمعية التعليم والتكنولوجيا وسائل الإعلام، وهي جميعها أشكال تستخدم في عملية توزيع المعلومات.بينما تحدد (AECT) جمعية التعليم (NEA) الأشياء التي يمكن التلاعب بها أو رؤيتها أو سماعها أو قراءها أو مناقشتها مع الأدوات المستخدمة جيدًا في أنشطة التعليم والتعلم، يمكن أن تؤثر على فعالية البرامج التعليمية.لذلك يمكن أن نستتج أن مفهوم الوسائل هو أمر يوجه الرسائل ويمكن أن يحفز ذهن الجمهور ومشاعره واستعداده (الطلاب) بحيث يمكنه تشجيع عملية التعليم عليه. سيمكّن الاستخدام الإبداعي لوسائل الإعلام الطلاب من التعلم بشكل أفضل ويمكنه تحسين حماسهم وفقًا للأهداف المراد تحقيقهات

\footnotetext{
'احمد، رحان، الوسائل التعليمية والتربيوية (جاكرتا: Rineka Cipta، Y997 1)، ص. r

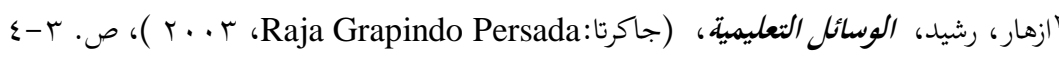

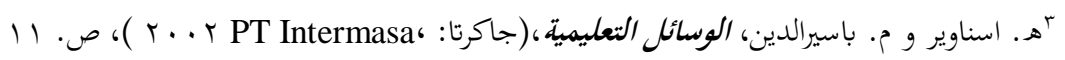


Thariqah IImiah: Jurnal IImu-IImu Kependidikan \& Bahasa Arab

Vol. 9. No. 1 Juni 2021

وفق daryanto، هي أداة تساعد عملية التعليم والتعلم التي تعمل على توضيح دعنى

$$
\text { الرسالة المرسلة حتى يمكن تحقيق أهداف التدريس جيدًا (أكثر كمالًا). }
$$

وأما وظيفة وسائل التعليم كما يقول هاماليك إن استخدام وسائل الإعلام التعليمية في

عملية التعليم والتعلم يمكن أن يزيد من رغبات واهتمامات جديدة، ويولد دافعًا وتحفيزًا لأنشطة التعلم، بل ويحاث تأثيرات نفسية عللالتلاميذ. إلى جانب توليد دوافع واهتمامات الطلاب، يمكن لوسائل التدريس أيضًا أن تساعدالتلاميذعلى تحسين الفهم، وتقديم البيانات بشكل جذاب وموثوق، وتسهيل تفسير البيانات، والمعلومات المدبجةه .

وفي البداية، عملت وسائل الإعلام فقط كأداة للتدريس والتعليم، وتحديداً في شكل منشآت يمكنها توفير بحربة بصرية للتلاميذمن أجل تشجيع التحفيز على التعليم وتوضيح وتبسيط المفاهيم المعقدة والمجردة لتكون أكثر بساطة وملموسة وأسهليفهم.وبالتالي يمكن أن تعمل وسائل الإعلام لتعزيز امتصاص الأطفال نخو التعليم.'

الكلمات المتقاطعة هي لعبة حيث طريقة اللعب هي ملء المساحات الفارغة في مربع بأحرف لتكوين كلمة تتوافق مع التعليمات.بالإضافة إلى أنه لغز الكلمات المتقاطعة والذي يُطلق عليه عادة TTS، إنه مفيد للغاية، بالإضافة إلى تذكر المفردات الشائعة، من المفيد أيضًا أن نضيف إلى معرفتنا العامة بطريقة مريحة.عند النظر إلى خصائص TTS المخففة التي تعطي الأولوية

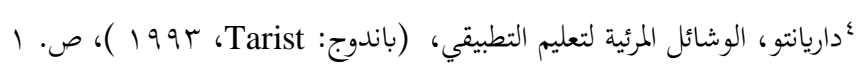

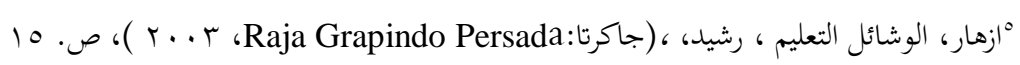

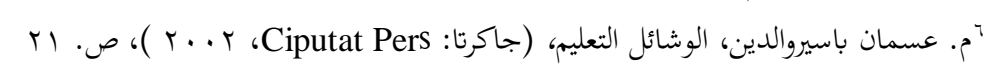


Thariqah Ilmiah: Jurnal Ilmu-IImu Kependidikan \& Bahasa Arab

Vol. 9. No. 1 Juni 2021

لأوجه التشابه والاختلاف في الكلمات، فإنها مناسبة جدًا إذا تم استخدامها على سبيل المثال

كوسيلة للطلاب لممارستها في مجتمع يقدمه المعلمون وليس رتابة في شكل أسئلة قياسية فقط.`

وأما المفردات مكون أساس من مكونات اللغة، بل ما اللغة إلا بجموعة من مفردات و كلمات.

و المفردات هي عنصر اللغة الذي يجب أن يتقن من قبل متعلمي اللغة الأجنبية لتكون

قادرة على اكتساب الكفاءة في التواصل مع تلك اللغة. لكن تعلم اللغات ليس متطابقًا من خلال تعليم المفردات فقط. بمعنى أن يكون لديك مهارات لغوية ليس فقط من خلال حفظ المفردات، لا يمكن لمتعلمي اللغة التعرف على اللغة من خلال القواميس.؟

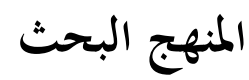

نوع البحث هو البحث في الفصل الدراسي، وهو عبارة عن دراسة تتعاونية بين الباحثة

والمدرسين والتلاميذ وغيرهم من موظفي المدرسة لإنشاء أداء مدرسي أفضل. البحث في الفصل الدراسي هو اختبار لأنشطة التعلم في شكل فعل يثار عمداً ويحدث في الفصل معًا. ،في تنفيذه، يتطلب هذا البحث تعاونًا نشطاً بين الباحثة والمدرسين والتلاميذ وموظفي المدرسة لخلق تعلم أفضل.حاولت الباحثة ملاحظة ووصف المشكات التي يعاني منها المعلم في تعلم المفردات. بعد ذلك، يهاول الباحثون والمدرسون توفير أعمال بديلة باستخدام صور الوسائل للتغلب على هذه

$$
\begin{aligned}
& \text { ^د. عبد الرمن بن إبرهيم الفوزان، إضاءات لمعلمي اللغة العربية لغير الناطقين بها، (الرياض: طبعت في المملكة العربية السعودي، } \\
& \text { \& } 2 \text { \&. } \\
& \text { 9احمد فؤاد منهج التعليم اللغة العربية،، (مالنج:مشكات، ه. . ب )، ص. } 97
\end{aligned}
$$


Thariqah IImiah: Jurnal IImu-IImu Kependidikan \& Bahasa Arab

Vol. 9. No. 1 Juni 2021

المشكلات. من المتوقع أن تكون الأعمال البديلة قادرة على المساهمة في تحسين التعلم وزيادة

مفردات اللغة العربية لتلاميذ. '

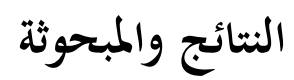

$$
\text { نتائج قبل الإجواء }
$$

استناد من نتيجة الامتحان قبل الإجراء معلوم أن الترقية الكتابة المفردات العربية خمسة و

ثلاثون شخصا الذي يكون وحدة البحث. يقدرون التلاميذ من الكتابة ولكن يجد الخطاء أن

ينظر من التابة المفردات والحركة المفردات العربية. للواضيح هذا دفتر التقدير الامتحان عن الترقية

الكتابة المفردات العربية من التلاميذ قبل الدورة.

\section{الجمدول الأول}

بينات نتائج قبل الإجراء (يوم السبت، في التاريخ ب • في الثهر أغسطس في السنة

\section{$(r+19$}

\begin{tabular}{|c|c|c|c|c|}
\hline تقدير & الحركة & الكتابة & إسم & رقم \\
\hline vo & rv & ґی & أحمد زكريا & 1 \\
\hline 7. & $r \cdot$ & $r \cdot$ & ألبار فرمونانجهن & r \\
\hline ^v & $\varepsilon \varepsilon$ & 纟o & أنيسا فطري & $r$ \\
\hline$\wedge r$ & « & $\varepsilon r$ & أليا ريهاني & $\varepsilon$ \\
\hline 10 & $\varepsilon r$ & $\varepsilon r$ & فهمي سليم عزيز & 。 \\
\hline 94 & $\{7$ & $\varepsilon 7$ & غوسنور اليمة & 7 \\
\hline 7. & $r$. & $r \cdot$ & هيكل البيحاقي & v \\
\hline$\vee \wedge$ & $\varepsilon \varepsilon$ & 纟o & حسنة البلدية & $\wedge$ \\
\hline $7 \varepsilon$ & rt & r & إحسان موردي & 9 \\
\hline Nr & « & «1 & ليرا أوليا & 1. \\
\hline$\wedge \uparrow$ & $\varepsilon r$ & $\varepsilon r$ & ماي زهرة & 11 \\
\hline
\end{tabular}

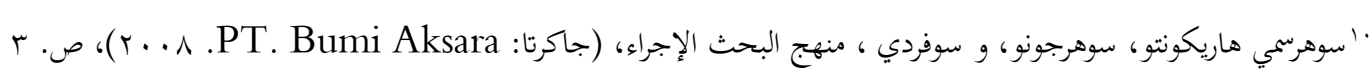


Thariqah Ilmiah: Jurnal Ilmu-IImu Kependidikan \& Bahasa Arab

Vol. 9. No. 1 Juni 2021

\begin{tabular}{|c|c|c|c|c|}
\hline NT & $\varepsilon 1$ & $\varepsilon 1$ & محمد واحد & Ir \\
\hline$\vee q$ & rq & $\varepsilon$. & نادي & $1 T$ \\
\hline 17 & $\varepsilon r$ & $\varepsilon r$ & نور أفيفة & $1 \varepsilon$ \\
\hline 10 & $\varepsilon r$ & $\varepsilon r$ & نور هنيفة & 10 \\
\hline 91 & $\varepsilon 7$ & $\varepsilon 0$ & أوكتفينا شفتري & 17 \\
\hline $9 r$ & $\varepsilon 7$ & $\varepsilon V$ & فوتري ننديني & IV \\
\hline 70 & rr & rr & رفلي مصاليح & 11 \\
\hline$\Lambda r$ & $\varepsilon 1$ & $\varepsilon 1$ & رحمة هداية & 19 \\
\hline$\Lambda \varepsilon$ & $\varepsilon r$ & $\varepsilon r$ & ريسكا أندرياني & $r$. \\
\hline NT & $\varepsilon 1$ & $\leqslant 1$ & رفيكا رهايو & YI \\
\hline VT & $\varepsilon r$ & $\varepsilon r$ & سهار أنيسا & rT \\
\hline 10 & $\varepsilon r$ & $\varepsilon r$ & سلسبيال & rr \\
\hline 10 & $\varepsilon r$ & $\varepsilon r$ & سيفا أنيال & $r \varepsilon$ \\
\hline$\wedge 7$ & $\varepsilon r$ & $\varepsilon r$ & سيفا موتيئ & ro \\
\hline NT & $\varepsilon 1$ & $\varepsilon 1$ & سيفا نور سيامي & ry \\
\hline 10 & $\varepsilon r$ & $\varepsilon r$ & سيلفا فضيلة & TV \\
\hline$\wedge \varepsilon$ & $\varepsilon r$ & $\varepsilon r$ & سيتي نور خليجة & rᄉ \\
\hline$\wedge 7$ & $\varepsilon r$ & $\varepsilon r$ & صفية أولفا & rq \\
\hline$\Lambda \varepsilon$ & $\varepsilon r$ & $\varepsilon r$ & تيغوة & $r$. \\
\hline חז & rr & ri & عمار بكرين & T \\
\hline$\wedge \varepsilon$ & $\varepsilon r$ & $\varepsilon r$ & فيفي أمندا & rt \\
\hline 10 & $\varepsilon r$ & $\varepsilon r$ & واردة فجيرة & rr \\
\hline$\vee \wedge$ & rq & rq & ولدان & $r \varepsilon$ \\
\hline Vo & rv & ry & محمد اديتيا & ro \\
\hline
\end{tabular}

استنادا إلى جدول الامتحان تستطيع أن ترى التلاميذ تكون الكاملة في التعليم 19

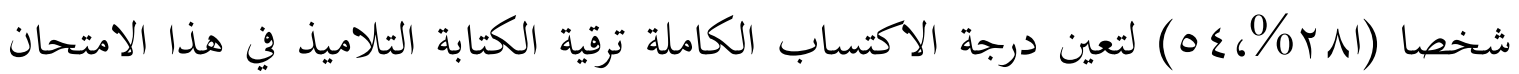
قبل الإجراء و يستطيع أن يرى بالطريقة التلي:

$\mathrm{P}=\underline{\text { Siswa yang tuntasbelajar }} \times 100 \%$

Esiswa

$=\underline{19} \times 100 \%$

35

$=54 \cdot 28$ 
Thariqah Ilmiah: Jurnal Ilmu-Ilmu Kependidikan \& Bahasa Arab

Vol. 9. No. 1 Juni 2021

نتائج الإجراء الأول

قبل يقوم الامتحان، بتد الترقية التقدير المتساوى التي قبلها (\%ءم، (ب) تكون

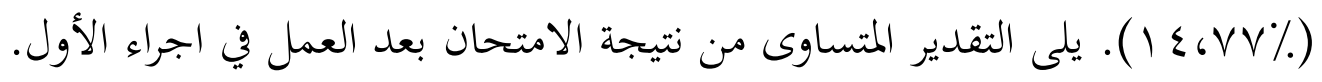

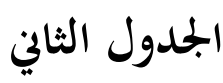

بينات نتائج الامتحان بعد العمل فياجراء الأول (يوم السبت، في التاريخ ـ ا في الشهر

أغسطس في السنة 9 ( ) م )

\begin{tabular}{|c|c|c|c|c|}
\hline تقدير & الحركة & الكتابة & إسم & رقم \\
\hline$\wedge$. & $\varepsilon$. & $\varepsilon$. & أحمد زكريا & 1 \\
\hline 79 & ro & $r \varepsilon$ & ألبار فرمونانجهن & r \\
\hline 91 & 纟o & $\leqslant 7$ & أنيسا فطري & $r$ \\
\hline ^v & $\varepsilon r$ & $\varepsilon \varepsilon$ & أليا ريهاني & $\varepsilon$ \\
\hline 19 & $\varepsilon \varepsilon$ & <0 & فهمي سليم عزيز & 。 \\
\hline $9 \varepsilon$ & $\varepsilon V$ & $\varepsilon V$ & غوسنور اليمة & 7 \\
\hline 79 & $r \varepsilon$ & ro & هيكل البيحاقي & v \\
\hline ᄉr & $\varepsilon r$ & \& & حسنة البلدية & $\wedge$ \\
\hline VI & rᄉ & ґی & إحسان موردي & 9 \\
\hline$\Lambda \varepsilon$ & $\varepsilon r$ & $\varepsilon r$ & ليرا أوليا & 1. \\
\hline 19 & $\varepsilon \varepsilon$ & $\varepsilon 0$ & ماي زهرة & 11 \\
\hline 10 & $\varepsilon r$ & $\varepsilon r$ & محمد واحد & ir \\
\hline$\wedge r$ & «1 & $\varepsilon r$ & 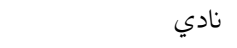 & ir \\
\hline 19 & $\varepsilon \varepsilon$ & $\varepsilon 0$ & نور أفيفة & $1 \varepsilon$ \\
\hline 9. & <0 & 纟o & نور هنيفة & 10 \\
\hline $9 r$ & $\leqslant 7$ & $\varepsilon V$ & أوكتفينا شفتري & 17 \\
\hline 90 & $\varepsilon \wedge$ & $\varepsilon \vee$ & فوتري ننديني & iv \\
\hline VV & ґی & rq & رفلي مصاليح & 11 \\
\hline 10 & $\varepsilon r$ & $\varepsilon r$ & رحمة هداية & 19 \\
\hline$\wedge$ & $\varepsilon \varepsilon$ & $\varepsilon \varepsilon$ & ريسكا أندرياني & $r$. \\
\hline 10 & $\varepsilon r$ & $\varepsilon r$ & رفيكا رهايو & YI \\
\hline$\wedge$ & $\varepsilon$ & $\varepsilon 1$ & سهار أنيسا & rr \\
\hline$\wedge$ & $\varepsilon \varepsilon$ & $\varepsilon \varepsilon$ & سلسبيلا & rr \\
\hline 19 & $\varepsilon \varepsilon$ & 纟o & سيفا أنيلا & $r \varepsilon$ \\
\hline 19 & $\varepsilon \varepsilon$ & $\varepsilon 0$ & سيفا موتيئ & ro \\
\hline
\end{tabular}


Thariqah Ilmiah: Jurnal Ilmu-IImu Kependidikan \& Bahasa Arab

Vol. 9. No. 1 Juni 2021

\begin{tabular}{|c|c|c|c|c|}
\hline$\Lambda \varepsilon$ & $\varepsilon r$ & $\varepsilon r$ & سيفا نور سيامي & T4 \\
\hline$\Lambda \wedge$ & $\varepsilon \varepsilon$ & $\leqslant \varepsilon$ & سيلفا فضيلة & TV \\
\hline 19 & $\varepsilon \varepsilon$ & $\varepsilon_{0}$ & سيتي نور خليجة & rᄉ \\
\hline 9. & 纟o & $\varepsilon_{0}$ & صفية أولنا & $r q$ \\
\hline$\Lambda \wedge$ & $\varepsilon \varepsilon$ & $\varepsilon \varepsilon$ & تيغوة & $r$. \\
\hline vo & rV & rᄉ & عمار بمرين & $r$ \\
\hline 19 & $\varepsilon \varepsilon$ & $\varepsilon_{0}$ & فيفي أمندا & rT \\
\hline$\Lambda$ & $\varepsilon \varepsilon$ & $\varepsilon \varepsilon$ & واردة فجيرة & $r r$ \\
\hline$\Delta r$ & $\varepsilon r$ & \&1 & ولدان & $r \varepsilon$ \\
\hline 11 & $\varepsilon$. & «1 & محمد اديتيا & ro \\
\hline
\end{tabular}

استناد إلى جدول الامتحان تستطيع أن ترى التلاميذ يكون الكاملة في التعليم rV

شخصا. نتائج هذا اجراء يدل فيه الرقية كما نتائج قبلال اجراء قبله ان الكاملة للتعليم عدده 9 1 شخصا. ولكن بعد تقوم الباحثة الامتحان في الدورة الأولى تكون VV شخصا الكاملة للتعليم. درجة الاكتساب الكاملة قدرة الكتابة التلاميذ في هذا الامتحاناجراء الأول يكون ( ) لتعيين درجة الاكتساب الكاملة و يستطيع أن يرى بالطريقة التلى: VV\% )

$\mathrm{P}=\underline{\text { siswa yang tuntasbelajar }} \times 100 \%$

Esiswa

$=\frac{27}{35} \times 100$

$=77.14$

نتائج اجراء الثاين

قبل يقوم الامتحان، بجد الرقية التقدير المتساوى الذي قبله ( ( ) ع ع ) يكون

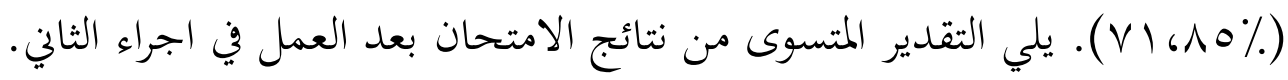


Thariqah IImiah: Jurnal IImu-IImu Kependidikan \& Bahasa Arab

Vol. 9. No. 1 Juni 2021

الجحداول الثالث

بينات نتائج الامتحان بعد العمل فياجراءالثاني(يوم أربعاء، في التاريخ ع ا في الثهر

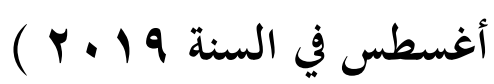

\begin{tabular}{|c|c|c|c|c|}
\hline تقدير & الحركة & الكتابة & إسم & رقم \\
\hline$\wedge \varepsilon$ & $\varepsilon r$ & $\varepsilon r$ & أحمد زكريا & 1 \\
\hline v. & $\varepsilon$. & $\varepsilon$. & ألبار فرمونانجهن & r \\
\hline $9 r$ & $\varepsilon 7$ & $\varepsilon V$ & أنيسا فطري & $r$ \\
\hline 9. & $\varepsilon 0$ & so & أليا ريهاني & $\varepsilon$ \\
\hline 94 & $\leq 7$ & $\leqslant 7$ & فهمي سليم عزيز & 0 \\
\hline 97 & $\varepsilon \wedge$ & $\varepsilon \wedge$ & غوسنور اليمة & 7 \\
\hline v. & ro & ro & هيكل البيحاقي & v \\
\hline$\Lambda \varepsilon$ & $\varepsilon r$ & $\varepsilon r$ & حسنة البلدية & $\wedge$ \\
\hline$\wedge 1$ & $\varepsilon$. & $\varepsilon 1$ & إحسان موردي & 9 \\
\hline$\Lambda T$ & $\varepsilon r$ & $\varepsilon r$ & ليرا أوليا & 1. \\
\hline 94 & $\{7$ & $\leqslant 7$ & ماي زهرة & 11 \\
\hline$\wedge \mathrm{T}$ & $\varepsilon r$ & $\varepsilon r$ & محمد واحد & Ir \\
\hline$\Lambda \varepsilon$ & $\varepsilon r$ & $\varepsilon r$ & نادي & ir \\
\hline 94 & $\leq 7$ & $\leqslant 7$ & نور أفيفة & $1 \varepsilon$ \\
\hline$q r$ & $\sum 7$ & $\varepsilon V$ & نور هنيفة & 10 \\
\hline 90 & $\sum V$ & $\varepsilon \wedge$ & أوكتفينا شفتري & 17 \\
\hline $9 \mathrm{~V}$ & $\leq 9$ & $\varepsilon \wedge$ & فوتري ننديني & iv \\
\hline$\lambda r$ & «1 & $\varepsilon 1$ & رفلي مصاليح & 11 \\
\hline 19 & $\varepsilon \varepsilon$ & $\varepsilon \varepsilon$ & رحمة هداية & 19 \\
\hline$q$. & 纟o & $\varepsilon 0$ & ريسكا أندرياني & $r \cdot$ \\
\hline 19 & $\varepsilon \varepsilon$ & ¿० & رفيكا رهايو & rI \\
\hline$\wedge \varepsilon$ & «1 & $\varepsilon r$ & سهار أنيسا & Tr \\
\hline 9. & so & $\varepsilon 0$ & سلسبيلا & rt \\
\hline 91 & $\leq 0$ & $\leq 7$ & سيفا أنيلا & $r \varepsilon$ \\
\hline 94 & $\{7$ & $\leq 7$ & سيفا موتيئ & ro \\
\hline$\wedge \vee$ & $\varepsilon \varepsilon$ & $\varepsilon r$ & سيفا نور سيامي & TY \\
\hline 91 & 纟o & $\leq 7$ & سيلفا فضيلة & TV \\
\hline 94 & $\leq 7$ & $\varepsilon 7$ & سيتي نور خليجة & rᄉ \\
\hline$q$ & $\leqslant 7$ & $\varepsilon V$ & صفية أولنا & rq \\
\hline 9. & 纟o & 纟o & تيغوة & $r$. \\
\hline$\wedge 1$ & $\varepsilon$. & $\varepsilon 1$ & عمار بهرين & $r 1$ \\
\hline 91 & $\leq 0$ & $\varepsilon 7$ & فيفي أمندا & rt \\
\hline 9. & $\leq 0$ & $\leq 0$ & واردة فجيرة & r \\
\hline$\wedge \varepsilon$ & $\varepsilon r$ & $\varepsilon r$ & ولدان & $r \varepsilon$ \\
\hline$\Delta r$ & $\varepsilon r$ & $\varepsilon 1$ & محمد اديتيا & ro \\
\hline
\end{tabular}


r. استناد إلى جدول الامتحان تسطيع أن ترى التلاميذ تكون الكاملة في التعليم شخصا. درجة الاكتساب الكاملة من الترقية الكتابة التلاميذ في الامتحان فإجراء الثاني يصل 160\% 1 1. بذلك استناد من نتائج الامتحان في إجراءالثاني ينفك هذا البحث لإن حصلت قصد الاكتساب الذي معين يعني بدرجة الاكتساب . م، ال لو كان خمسة التلاميذ لم يكمل في التعليم. لتعين درجة الاكتساب الكاملة من الترقية الكتابة التلاميذ في الامتحانإجراءالثاني ان

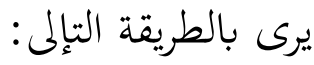

$\mathrm{P}=\underline{\text { Siswa yang tuntasbelajar }} \times 100 \%$

\section{Ssiswa}

$=\underline{30} \times 100$

35

$71 \cdot=85$

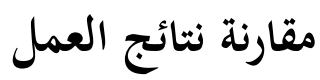

استناد من المقرنة التقدير النتائج قبل الإجراء، إجراءالأولإجراءالثاني يجد بيانات ان تكون

ترقية من التقدير المتوسطة الكتابة المفردات العربية التلاميذ في إجراء الأول و الثاني.

$$
\text { الجدول الرابع }
$$

\begin{tabular}{|c|c|c|}
\hline درجة الاكتساب & عدد التلاميذ الكامل التعليم & العمل ل كمل \\
\hline rA, $0 \% \%$ & 19 & قبل التجريب \\
\hline $1 \varepsilon_{6} \vee V \%$ & rV & التجريب الأول \\
\hline$V 1,10 \%$ & $r$. & التجريب الثاني \\
\hline
\end{tabular}




$$
\text { مقارنة من نتائج قبل الإجراء،إجراء الأول وإجراءالثاني }
$$

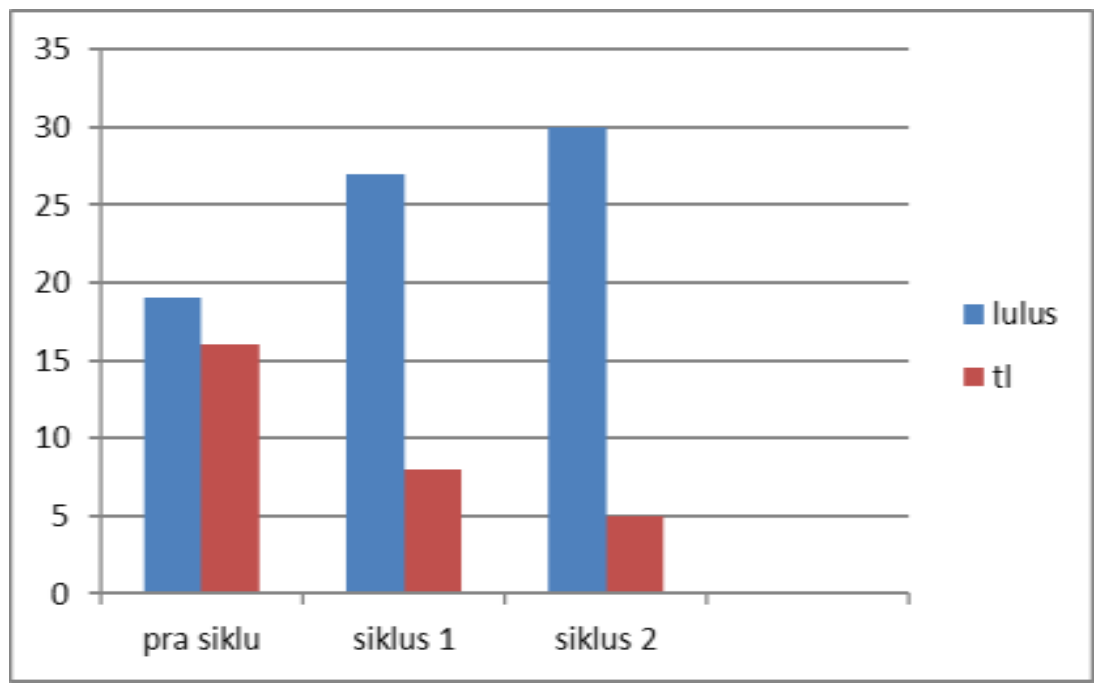

استناد إلى الجدول الامتحان ترقية الكتابة قدرة الكتابة ارتفاع، من قبل الإجراء ملحق

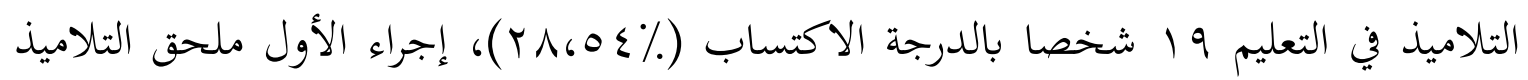
في التعليم V شحصا بالدرجة الاكتساب (. \& \& I I ) و إجراء الثاني ملحق التلاميذ في التعليم

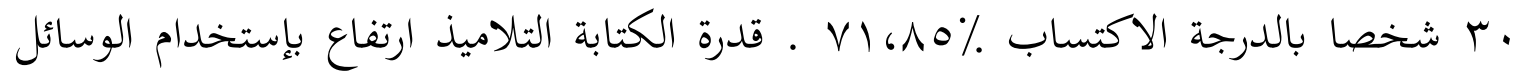
كلمات المتقاطعة، لإن الوسائل كلمات المتقاطعة أحسن ليستعمل في تعليم المهارة الكتابة.

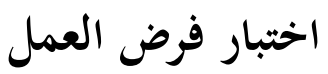

فرض العمل من هذا البحث هو"استخدام وسائل كلمات المتقاطعة لترقية قدرة كتابةالمفرداتاللغة العربيةلتلاميذالفصل الثامن في مدرسة المتوسطة الإسلامية الحكومية ب بادانج سيديمبوان ". استناد إلى الامتحان الباحثة يعلم قدرة من التلاميذ ارتفاع من قبل التجريب، إجراء الأول و إجراء الثاني. استناد من نتيجة الامتحان والملاحظة فرض العمل من هذا البحث هو 
استخدام وسائل كلمات المتقاطعة لترقية قدرة كتابةالمفرداتاللغة العربيةلتاميذالفصل الثامن في المدرسة المتوسطة الإسلامية الحكومية ب بادانج سيديمبوان مقبول.

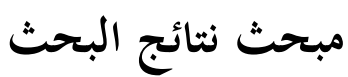

استناد من نتائج البحث، هذا البحث لجحت ليل المقصود الذي قد تمت، يعني قدرة

الكتابة بوسائل كلمات المتقاطعة في مدرسة المتوسطة الإسلامية الحكومية ب بادانج سيديمبوان،هذا الحال أن يرى في مقارنة النتيجة في التعليم من فبل الإجراء، إجراء الأول و إجراء الثاني متزايد. بإستخدام الوسائل كلمات المتقاطعة التلاميذ ليس ماهر بالكتابة فقط و لكن الحماسة و الرعبة من التلاميذ في عملية التليم ارتفاع. غير يعمل الامتحان لترى ترقية قدرة الكتابة التلميذ تنظر الباحثة في توجهات الملاحظة التوفرة الت تلاحظ أداء في عملية التعليم. نتيجة الملاحظة تدل غلى الترقية القدرة الكتابة المفردات العربية التلاميذ.

قدرة الكتابة المفردات العربية من التلاميذ بوسائل كلمات المتقاطعة ارتفاع مناسب من متوقع الباحثة. وسائل كلمات المتقاطعة مناسب لتستعمل في غملية التعليم تاعربية خاصة في ترقية الكتابة من التلميذ، بوسيلة كلمات المتقاطعة فيه جذاب كثير من التلاميذ. و نتيجة التعليم مشغول و سرور، حتى تسهل التلاميذ في فهم الدراسة قد شرح، و تزد الحماسة و الرعبة التلاميذ في التعليم. لأن بوسيلة كلمات المتقاطعة تتابعون التلاميذ في عملية التعليم متحمسة، ثم مشترك 
Thariqah IImiah: Jurnal IImu-IImu Kependidikan \& Bahasa Arab

Vol. 9. No. 1 Juni 2021

بين التلاميذ في عملية التعليم بخير، و تشحع التلاميذ للمشغول، و يشند الابتكار التلاميذ في عملية التعليم.

استناد إلى تقديم الامتحان، أن قدرة الكتابة المفردات العربية من التلاميذ بإستخدام

وسائل كلمات المتقاطعة ارتفاع. و ينظر في تقدير قبل الإجراء، إجراء الأول، وإجراءالثاني ارتفاع من كل الإجراء.

الحخلاصة

استناد إلى الدراسة الذي شرح في أبواب قبله، تتم الباحثة من نتيجة البحث هو ترقية

قدرة الكتابة التلاميذ بوسيلة كلمات المتقاطعة في مدرسة المتوسطة الإسلامية الحكومية ب بادانج

سيديمبوان. و ينظر النتيجة من الاكتساب التقدير قبل إجراء9 اشخصا او \% م،، عه، إجراء

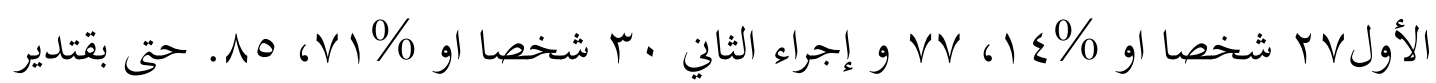
الاكتساب نظر النتيجة البحث واضح و فيه الترقية. 


$$
\text { أملمد فؤاد منهج التعليم اللغة العربية،، (مالنج:مشكات، م . . ب ) }
$$

أحمد، رحان، الوسائل الثعليمية التربوية، (جاكرتا: Rineka Cipta، 9 V )

أزهار، رشيد، الوسائل الثعليمية، (جاكرتا:Raja Grapindo Persada، ب . . ب )

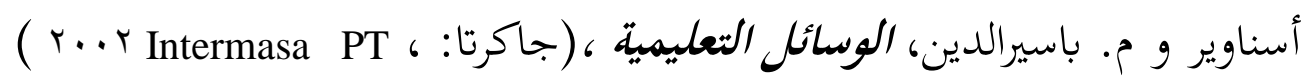

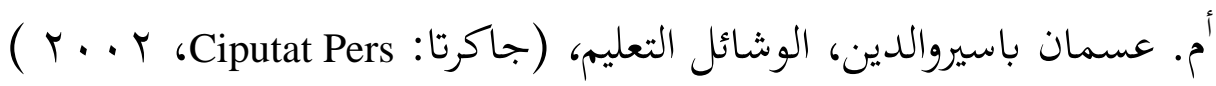

داريانتو، الوشائل الموئية لتعليم التطبيقي، (باندوج: Tarist، م99 1 )

رشيد أزهار ، الوشائل التعليم، (جاكرتا:Raja Grapindo Persada، ب . . ب )

سوهرسمي هاريكونتو، سوهرجونو، و سوفردي ، منهج البحث الإجراء، (جاكرتا: PT. Bumi

$$
(\curlyvee \cdot \Lambda \cdot \text {.Aksara }
$$

عبد الرحمن بن إبرهيم الفوزان، إضاءات لمعلمي اللغة العربية لغير الناطقين جما، (الرياض: طبعت

$$
\text { في المملكة العربية السعودي، هم؟ ا هـ) }
$$

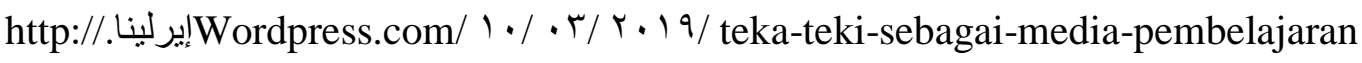

